\title{
Breast milk jaundice in premature infants
}

\author{
A LUCAS AND B A BAKER \\ MRC Dunn Nutrition Unit and University Department of Paediatrics, Cambridge
}

SUMMARY In a randomised study of 186 preterm infants those fed on maternal or banked breast milk had a significantly higher peak bilirubin concentration and a more prolonged jaundice than infants fed an artificial preterm formula and were over four times more likely to achieve plasma bilirubin values above $200 \mu \mathrm{mol} / 1(11.7 \mathrm{mg} / 100 \mathrm{ml})$. This dietary effect was seen even in a high risk subgroup of sick ventilated infants below $1500 \mathrm{~g}$ who were receiving restricted enteral intakes. We suggest that breast milk jaundice in preterm infants may increase clinical intervention. Our findings are discussed in the light of epidemiological data suggesting an association between moderate hyperbilirubinaemia $(>170 \mu \mathrm{mol} / \mathrm{l})$ and neurodevelopmental outcome.

A small percentage of full term infants develop pronounced and prolonged breast milk jaundice. A more general tendency of breast fed infants to achieve higher plasma bilirubin concentrations than those fed with formula has been observed by some groups but not by others. ${ }^{1}$ There have been few detailed longitudinal studies, however, on breast milk jaundice in infants born preterm; yet, as discussed below, a diet induced increase in plasma bilirubin concentration might be of greater clinical importance in this high risk subgroup than in the full term neonate. In this study we have examined the relation between diet, respiratory disease, birth weight, and plasma bilirubin concentrations in 186 infants born in one unit taking part in a larger, randomised multicentre dietary trial.

\section{Subjects and methods}

One hundred and eighty six preterm infants weighing less than $1850 \mathrm{~g}$ at birth, with a mean (SD) gestation of 31 (3) weeks and mean (SD) birth weight of 1385 (291) g, were studied.

Infants whose mothers elected not to provide their own milk were assigned randomly to receive either banked donor breast milk or a special preterm infant formula (Oster-Prem, Farley Health Products Ltd) as sole diets (primary trial). When mothers expressed their own 'preterm' milk the infants were assigned randomly to receive either banked breast milk or preterm formula as 'supplements' to their mother's milk in volumes according to the mother's success in expressing her milk (supplement trial).
(The randomisation procedure is described in detail elsewhere. ${ }^{2}$ )

The median intake of maternal milk in the supplement trial was $46 \%$ of the total milk volume consumed.

Infants were studied until they reached a weight of $2000 \mathrm{~g}$ or were discharged from hospital. A blood sample, taken (for multiple purposes) at the time of routine clinical monitoring, was analysed for total plasma bilirubin concentration on the following mean (SD) days postpartum; 2(1), 5(1), 11(2), 18(2), 25(2), 34(3), and 50(7).

This study was designed to detect differences in bilirubin concentrations between randomised feed groups and not to derive 'normal' standards for plasma bilirubin in relation to diet. Our standardised blood sampling protocol would fail to detect the peak bilirubin value in some instances when this occurred on an intervening day (and thus our figures slightly underestimate maximum values in all feed groups).

Total plasma bilirubin was measured by the Jendrassik-Grof reaction, using a Roche kit in a centrifugal autoanalyser (Cobas Bio).

Ethical approval for the trial as a whole was obtained from the hospital ethical committees. Statistical analyses were performed using Student's $t$ test, $\chi^{2}$ test with Yates's correction, and Fisher's exact probability test.

\section{Results}

Details of the study population are shown in Table 1. 
There was no difference between feed groups in mean gestation, birth weight, proportion receiving mechanical ventilation, or volume of intake of enteral feed during the first week. During the course of the study, the total number of subjects remaining in the study declined as follows: day 2, 186; day 5, 186 ; day 11,182 ; day 18,166 ; day 25,140 ; day 34 , 98 ; and day 50,64 . In the last period (34-50 days) there was a sharp fall in the proportion of subjects fed on the formula as a result of their faster growth rate on this diet and hence earlier discharge from hospital.

Figure 1 and Table 2 show that for each feed group the highest mean bilirubin concentration was seen at the second sampling period (day range 4-7, mean 5). At this age infants in the primary trial (Fig. 1) fed on banked breast milk had a significantly higher plasma bilirubin concentration than those fed on the preterm formula, 196 (SE 14) $\mu \mathrm{mol} / \mathrm{l}(11.5$ $(0 \cdot 8) \mathrm{mg} / 100 \mathrm{ml})$ compared with $147(15) \mu \mathrm{mol} / \mathrm{l}$ $(8.6(0.9) \mathrm{mg} / 100 \mathrm{ml})(\mathrm{p}<0.02)$. The subsequent decline in bilirubin concentrations was slower on banked breast milk: by a mean of 25 days, bilirubin concentrations were $76(12) \mu \mathrm{mol} / \mathrm{l}$ on banked breast milk compared with 27 (7) $\mu \mathrm{mol} / \mathrm{l}$ on the preterm formula $(\mathrm{p}<0 \cdot 001)$. Also in the comparison of the supplement trial (Table 2), infants fed banked

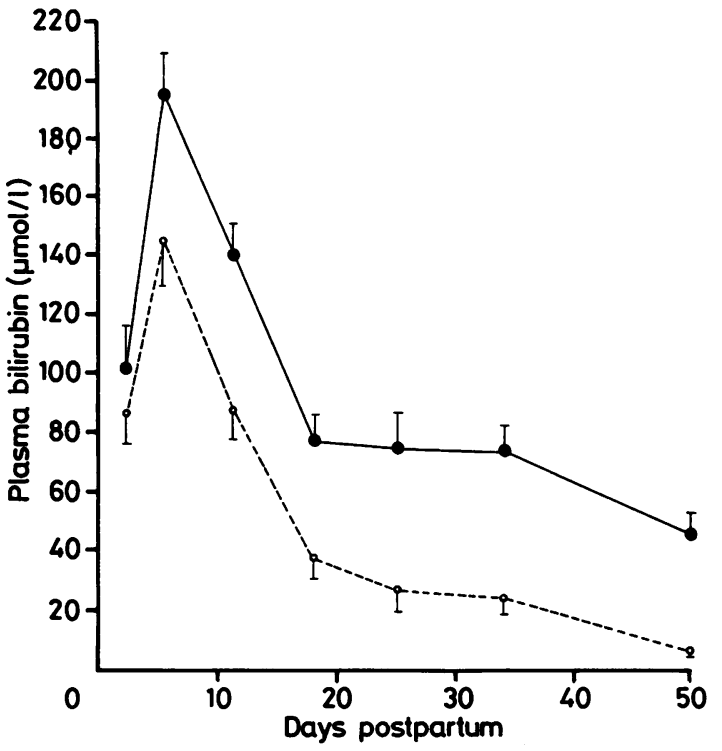

Fig. 1 Change in total (SE) plasma bilirubin concentrations ( $\mu \mathrm{mol})$ with postnatal age in infants fed banked breast milk (-) compared with those fed a special preterm infant formula $\left(\mathrm{O}_{-}-\mathrm{O}^{-}\right)$as sole diets.

Conversion: SI to traditional units-Bilirubin: $1 \mu \mathrm{mol} / \mathrm{I} \approx 0.06 \mathrm{mg} / 100 \mathrm{ml}$.

Table 1 Details of study population ( $n=186)$ classified by diet

\begin{tabular}{|c|c|c|c|c|c|}
\hline Diet & $\begin{array}{l}\text { Initial No of } \\
\text { subjects } \\
\text { entering study }\end{array}$ & $\begin{array}{l}\text { Mean (SE) } \\
\text { gestation } \\
\text { (weeks) }\end{array}$ & $\begin{array}{l}\text { Mean }(S E) \\
\text { birth weight } \\
(g)\end{array}$ & $\begin{array}{l}\text { No of subjects } \\
\text { ventilated }\end{array}$ & $\begin{array}{l}\text { Total (SE) enteral feed } \\
\text { volume/kg body weight } \\
\text { during first week }(\mathrm{ml})^{*}\end{array}$ \\
\hline \multicolumn{6}{|l|}{ Primary trial: } \\
\hline BBM & 29 & $31(0 \cdot 6)$ & $1409(56)$ & 15 & $628(112)$ \\
\hline PTF & 30 & $31(0 \cdot 6)$ & $1372(55)$ & 17 & $596(87)$ \\
\hline \multicolumn{6}{|l|}{ Supplement trial: } \\
\hline $\mathrm{EBM}+\mathrm{BBM}$ & 62 & $31(0.4)$ & $1378(36)$ & 26 & $606(53)$ \\
\hline $\mathrm{EBM}+\mathrm{PTF}$ & 65 & $31(0.4)$ & 1388 (37) & 29 & $597(58)$ \\
\hline
\end{tabular}

BBM=Banked breast milk; PTF=preterm infant formula; EBM=expressed maternal breast milk.

Conversion: SI to traditional units-Bilirubin: $1 \mu \mathrm{mol} / \approx 0.06 \mathrm{mg} / 100 \mathrm{ml}$.

* Overall mean (SD) enteral feed volume during the first week in ventilated infants was 232 (27) ml and in non-ventilated infants was 917 (39) ml.

Table 2 Comparison of mean (SE) plasma bilirubin concentrations ( Hmolll) in infants fed on either banked breast milk $(B B M)$ or preterm formula $(P T F)$ as supplements to expressed maternal breast milk (median intake of maternal milk was $47 \%$ and $45 \%$, respectively)

\begin{tabular}{|c|c|c|c|c|c|c|c|}
\hline \multirow[t]{2}{*}{ Diets } & \multicolumn{7}{|c|}{ Days of age } \\
\hline & 2 & 5 & 11 & 18 & 25 & 34 & 50 \\
\hline EBM+BBM $(n=62) \dagger$ & $105(10)$ & $188(9)^{*}$ & $139(11)^{*}$ & $98(10)$ & $85(12)^{*}$ & $44(16)$ & $16(2)$ \\
\hline
\end{tabular}

Conversion: SI to traditional units-Bilirubin: $1 \mu \mathrm{mol} / \mathrm{I} \approx 0.06 \mathrm{mg} / 100 \mathrm{ml}$. ${ }^{*} \mathrm{p}<0 \cdot 05$.

†No of subjects entering study. 
breast milk as a supplement to maternal expressed milk had higher concentrations of bilirubin on days 5 , 11, and 25 than those seen when expressed maternal milk was supplemented with formula $(p<0.05)$, though the difference was smaller than in the primary trial.

There was no influence of birth weight on 'peak' bilirubin concentration (which did not always occur at days 4-7 in individual infants). Infants who were mechanically ventilated, however, had higher overall mean peak bilirubin values compared with infants not requiring ventilation: 190(SE 7) $v 151$ (7) $\mu \mathrm{mol} / \mathrm{l}(\mathrm{p}<0.001)$. As very low birthweight infants who are sick possibly carry the greatest risk of

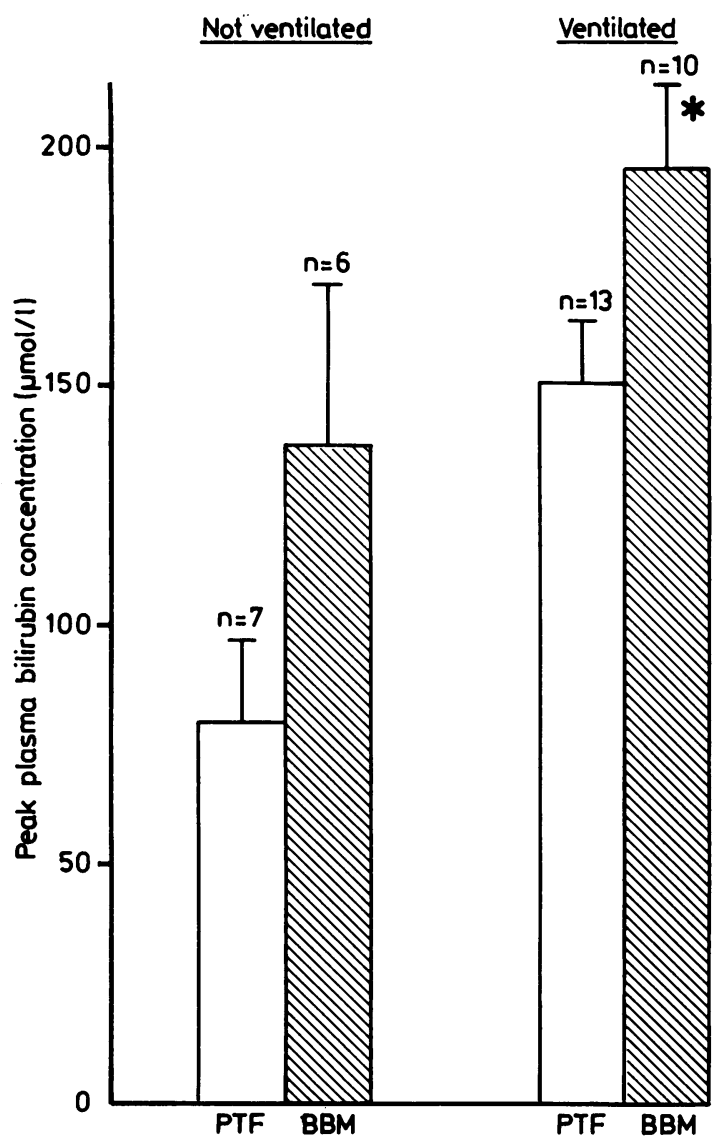

Fig. 2 Effect of preterm formula (open columns) or banked breast milk (hatched columns) on highest recorded ('peak') (SE) bilirubin concentration ( $\mu$ mol/l) in infants with birth weight under $1500 \mathrm{~g}$ who were (right) and were not (left) mechanically ventilated.

${ }^{*} \mathrm{p}<0 \cdot 05$.

Conversion: SI to traditional units-Bilirubin: $1 \mu \mathrm{mol} / \approx 0.06 \mathrm{mg} / 100 \mathrm{ml}$. bilirubin neurotoxicity we performed a preliminary analysis on peak plasma bilirubin of those infants with birth weight below $1500 \mathrm{~g}$ who had been randomly assigned to banked milk or formula as sole diets (primary trial). Figure 2 shows that in this subgroup infants who were ventilated had significantly higher mean peak bilirubin concentrations if they were fed on banked breast milk rather than preterm formula: $195(18) \mu \mathrm{mol} / \mathrm{l}$ compared with 151 (11) $\mu \mathrm{mol} / \mathrm{l}(\mathrm{p}<0.05)$. The effect of diet in the non-ventilated group below $1500 \mathrm{~g}$ did not reach significance, though the population size was small (Fig. 2). The mean enteral feed volume intake in the first week in ventilated infants weighing less than $1500 \mathrm{~g}$ (primary trial) was only 195 (SE 52) ml compared with 822 (39) $\mathrm{ml}$ in the non-ventilated group $(\mathrm{p}<0.001)$; there was no difference in volume intake between diet groups in either case.

In Figure 3 subjects of all birth weights are grouped according to their highest recorded (peak) bilirubin value and a non-randomised, epidemiological comparison is made between infants fed on

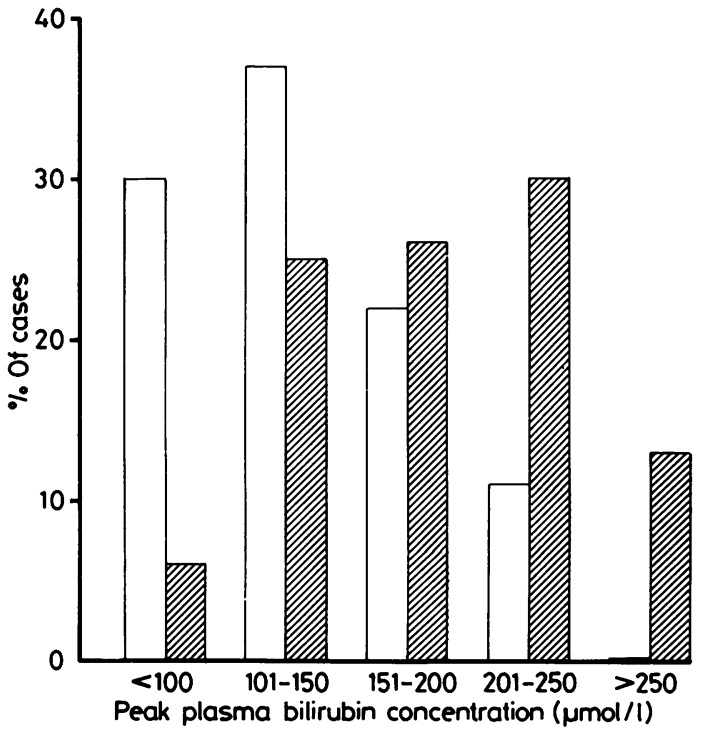

Fig. 3 Percentage of subjects fed on preterm formula $(n=30)$ (open columns) or human milk (banked breast milk or expressed maternal breast milk supplemented with banked breast milk, $n=94$ ) (hatched columns) grouped according to highest recorded ('peak') plasma bilirubin concentration ( $\mu \mathrm{mol} / \mathrm{l}$ ).

By $\chi^{2}$, significantly higher proportion of formula fed infants with peak values $<100 \mu \mathrm{mol} / \mathrm{l}$ and significantly lower proportion with values $>200 \mu \mathrm{mol} / /$ $(\mathrm{p}<0 \cdot 01)$.

Conversion: SI to traditional units-Bilirubin: $1 \mu \mathrm{mol} / \mathrm{l} \approx 0.06 \mathrm{mg} / 100 \mathrm{ml}$. 
formula alone and those fed on human milk (banked milk alone or expressed maternal milk supplemented, when required, with banked milk). Infants in the two groups fed human milk were combined as mean peak bilirubin values in each case were not significantly different. The proportion of infants whose highest recorded values did not exceed $100 \mu \mathrm{mol} / \mathrm{l}$ was significantly higher in the group fed formula $(9 / 30: 30 \%)$ than in the combined groups fed human milk $(6 / 94: 6 \%)\left(\chi^{2}=9 \cdot 8, p<0 \cdot 01\right)$. Conversely, a significantly higher proportion of infants fed human milk had their highest values over $200 \mu \mathrm{mol} / 1 \mathrm{(40/94:43 \% )}$ compared with the group fed preterm formula $(3 / 30: 10 \%)\left(\chi^{2}=9 \cdot 3, p<0 \cdot 01\right)$.

\section{Discussion}

In this randomised study preterm infants fed on human milk had higher peak concentrations of plasma bilirubin and more prolonged hyperbilirubinaemia than those fed on an artificial preterm infant formula. This dietary effect was apparent even with low feed volumes and was found in sick ventilated infants below $1500 \mathrm{~g}$ (Fig. 2) whose mean intake of banked breast milk or formula during the first week was only $200 \mathrm{ml}$.

A notable feature of a rise in plasma bilirubin concentration induced by breast milk, especially that seen with banked donor milk, is its persistence. Indeed, a major proportion of infants fed human milk who remained in hospital until 5-7 weeks postpartum were still frankly jaundiced (Fig. 1); some were investigated to exclude other causes. Although the number of infants at this analysis was too small to explore adequately an effect of diet on the need for either phototherapy or exchange transfusions, preliminary data suggest that both the use of phototherapy and the duration of its application tended to be greater in infants fed human milk than in those fed formula; this may have had the effect of reducing the potential difference in bilirubin concentrations between feed groups. The possibility that breast milk jaundice increases clinical intervention needs further exploration.

The most important question arising from our findings is whether or not diet induced hyperbilirubinaemia could have neurological sequelae. The neurotoxic effects of bilirubin are well established, yet the peak bilirubin concentration achieved by individual preterm infants has limited value for predicting neurological damage. ${ }^{3}$ Thus while some infants may tolerate high concentrations of bilirubin without apparent consequences, others may develop frank kernicterus at low plasma bilirubin concentrations. ${ }^{4-6} \mathrm{~A}$ number of factors have been identified that may influence bilirubin neurotox- icity; these include the binding of bilirubin to albumin or cells and the integrity of the blood-brain barrier, which may be affected in turn by asphyxia and acidosis. ${ }^{7-10}$ Nevertheless, one large epidemiological study showed that for large populations there is an apparent, overall 'dose-response' relation between plasma bilirubin and motor delay. ${ }^{11}$ The same study also showed an association between quite modest rises of plasma bilirubin -around $200 \mu \mathrm{mol} / \mathrm{l}$-and such neurodevelopmental effects, especially in infants born preterm. Stewart reported that a bilirubin concentration of greater than $170 \mu \mathrm{mol} / \mathrm{l}$ was a significant factor associated with neurological handicap and sensorineural hearing loss in preterm infants. ${ }^{12}$ Moreover, a variety of clinical and experimental studies have shown that the persistence of hyperbilirubinaemia may be a critical factor in determining the extent of neurological damage.${ }^{14}$ In the present study peak bilirubin values over $200 \mu \mathrm{mol} / \mathrm{l}$ (Fig. 3) were about four times more common in infants fed human milk (incidence $43 \%$ ) than in those fed formula (incidence $10 \%$ ).

Possibly the most vulnerable infants for bilirubin neurotoxicity are those of very low birth weight who have respiratory disease, which is commonly associated with low plasma albumin concentration and acidosis. It might be supposed that these infants would not be influenced by the type of milk chosen, as enteral intakes are usually limited in sick neonates. Yet our preliminary data show that even in this subgroup small volumes of human milk cause a significantly greater rise in plasma bilirubin than that seen with formula. Furthermore, we have shown that plasma bilirubin concentrations are higher in any case in infants with severe respiratory disease.

Despite these considerations, an epidemiological association between modest hyperbilirubinaemia and adverse neurodevelopmental effects does not imply necessarily a causal relation, and further work is needed in this area. The infants in this study represent a subgroup of over 900 babies from a multicentre feeding trial, and during their follow up (in progress) the relation between early diet, hyperbilirubinaemia, and subsequent neurological development is being examined. Given the information currently available, however, it might be unwise to disregard breast milk jaundice in high risk low birthweight infants. Temporary stopping of breast feeding ( 48 hours) has been used with success in full term infants with pronounced breast milk jaundice. ${ }^{1}$ We speculate that brief stopping of human milk feeds might prove valuable in certain preterm infants, especially those who are sick, as an adjunct to other measures in the treatment and prophylaxis 
of hyperbilirubinaemia, though further investigation is required to explore the clinical consequences of such a manoeuvre.

We thank the staff of the Special Care Baby Unit, Rosie Maternity Hospital, Cambridge, for their help and cooperation, P J Lucas for help with blood sampling. Farley Health Products for help and supply of the preterm formula, and P A Simpson for technical help.

\section{References}

1 Maisels MJ. Neonatal jaundice. In: Avery GB, ed. Neonatology: pathophysiology and management of the newborn. Philadelphia: JB Uppincott, 1981:473-544.

2 Lucas A, Gore SM, Cole TJ, et al. A multicentre trial on the feeding of low birthweight infants: effects of diet on early growth. Arch Dis Child 1984;59:722-30.

${ }^{3} \mathrm{Kim} \mathrm{MH}$, Yoon JJ, Sher J, et al. Lack of predictive indices in kernicterus: a comparison of clinical and pathologic factors in infants with and without kernicterus. Pediatrics 1980;66:852-8.

4 Cashore WJ, Oh W. Unbound bilirubin and kernicterus in low-birthweight infants. Pediatrics 1982;69:481-5.

5 Ritter DA, Kenny JD, Norton J, et al. A prospective study of free bilirubin and other risk factors in the development of kernicterus in premature infants. Pediatrics 1982;69:260-6.

' Gartner LM, Snyder RN, Claboni RS, Bernstein J. Kernicterus: high incidence in prematures with low serum bilirubin concentrations. Pediatrics 1970;45:906-17.
${ }^{7}$ Odell GB. Studies in kernicterus 1. The protein binding of bilirubin. J Clin Invest 1959:38:823-33.

${ }^{8}$ Kozuki K. Cashore WJ, Widness J, Oh W. Increase in bilirubinalbumin binding affinity with correction of neonatal acidosis. Acta Paediatr Scand 1979;68:213-7.

${ }^{9}$ Mustafa M, King TE. Binding of bilirubin with lipid: a possible mechanism of its toxic reactions in mitochondria. J Biol Chem 1970;345:1084-9.

11 Luccy JF, Hibbard E, Behrman RD, et al. Kernicterus in asphyxiated newborn rhesus monkey. Exp Neurol 1964;9:43-58.

"Scheidt PC, Mellits ED, Hardy JB, Drage JS, Boggs TR. Toxicity to bilirubin in neonates: infant development during first year in relation to maximum neonatal serum bilirubin concentration. J Pediatr 1977;91:282-7.

12 Stewart A. Severe perinatal hazards. In: Rutter M, ed. Developmental psychiatry. New York: Guildford Press, 1983:15.

13 Abramovich SJ, Gregory S, Slemick M, Stewart AL, Hearing loss in very-low-birthweight infants treated with intensive care. Arch Dis Child 1979;54:421-6.

14 Johnson L, Boggs T. Bilirubin dependent brain damage: incidence and indications for treatment. In: Odell GE, Simopoulos AP, Shaffer R, eds. Phototherapy in the newborn: an overview. Washington DC: National Academy of Sciences, 1974:122-49.

Correspondence to Dr A Lucas, Dunn Nutritional Laboratory, Downhams Lane, Milton Road, Cambridge CB4 1XJ, England.

Received 30 June 1986 